\title{
Luang Pradit Phairoh (Sorn Silapabanleng): Transmission and Development of Thai Classical Music
}

\author{
Pamon Pootong1, Jarernchai Chonpairot ${ }^{1}$, Sangkom Pumipuntu ${ }^{2}$ \\ ${ }^{1}$ College of Music, Mahasarakham University, Maha Sarakham, Thailand \\ ${ }^{2}$ Faculty of Education, Mahasarakham University, Maha Sarakham, Thailand \\ Email: music@phong-nguyen.com
}

Received 7 December 2015; accepted 15 February 2016; published 18 February 2016

Copyright (C) 2016 by authors and Scientific Research Publishing Inc.

This work is licensed under the Creative Commons Attribution International License (CC BY). http://creativecommons.org/licenses/by/4.0/

(c) (;) Dpen Access

\begin{abstract}
This study is a qualitative research project. The aims are to: 1) Study the transmission methods of Thai classical music from Luang Pradit Phairoh (his birth name: Sorn Silapabanleng) and 2) Study the development methods of Thai classical music from Luang Pradit Phairoh. Research instruments used in the study were a preliminary survey, structured interview, unstructured interview and in-depth interview to explore information by 15 persons from key informants and 13 casual informants. The research was conducted from September 2010 to December 2012. The data were checked for accuracy by means of triangulation. The purpose of the set and results were presented by descriptive analysis. The findings are the following: 1) The transmission of Thai classical music from Luang Pradit Phairoh is believed to be based for acceptance on attendance to class tradition, in which parents entrust their children to teachers' care. Then there is the ceremony of hand grasping for the beginning. Teacher's houses are employed as schools. Demonstration is applied with oral transmission from the ability of each student. 2) Luang Pradit Phairoh has developed a way to play ranat-ek (a high-tone xylophone) in practicing various performance styles. The theme songs written by Luang Pradit Phairoh have been performed widely, and some have been composed from the intonation of foreign countries such as Mon, Khmer and Java. Luang Pradit Phairoh invented the angklung and written notation of Thai music has been created. The students of Luang Pradit Phairoh had inherited the music style of their teacher to earn a living and transferred to their pupils.
\end{abstract}

\section{Keywords}

Transmission, Development, Thai Classical Music 


\section{Introduction}

Luang Pradit Phairoh (his birth name: Sorn Silapabanleng) had been gifted with musical talents since he was a child. When he turned five years old, he was able to play kong wong yai or gong circle. Moreover, at eleven, he started learning piphat (Thailand's typical classical orchestra) from his father, Sin Silapabanleng, an exceptionally talented musician from Amphawa in Samut Songkhram province. Since Luang Pradit Phairoh was a man with musical prowess who had been well-groomed by his father's ways of teaching, he was overwhelmed with knowledge and incredible skills in Thai classical music field and developed very quickly. He could also play ranad wai jud since he was a child. In 1899, His Royal Highness Panurangsi Swangwong Krom Praya Panuphat Woradej appointed him as his ranat-ek player in the royal page position and named him “Jang Wang Sorn.” Because of his expertise in Thai classical music, His Majesty the King Mongkut Klao Chao Yu Hua named him as “Luang Pradit Phairoh" on July 17 $7^{\text {th }} 1925$ despite the fact that he had never been employed in any diplomatic field before.

Luang Pradit Phairoh was an imaginative musician with wide visions. He invented and improved various methods of playing ranat-ek, a high-tone xyplophone. He had competed with a large number of the greatest ranat-ek players and never lost. Most importantly, his ranat-ek compositions were widely appreciated. He improved the song "Khmer Kao Kiaw" from two to three bars. He smoothened and sweetened tones and notes, causing huge differences between the old and new version. Then he renamed this song to "Khmer Liab Nakorn.” He also invented lyrical songs (known in Thai as rub, rong, and oh songs). He first started composing songs with three and four bars, for example "Pama Ha Ton 4 bars," "Prahm Deed Nam Tao 4 bars," "Dao Jira Kewith 4 bars," and "Khmer Sai Yok 4 bars.” Furthermore he improved Thai bands and changed a large amount of Thai classical songs to Tao songs. In addition, his songs are widely appreciated since every single one of them was beautifully composed, melodious and distinctive in their own ways.

He had composed more than a hundred songs such as those in the hom rong type of songs, Tao as well as Mon types of songs. He also wrote songs with different accents such as "Prahm Deed Nam Tao," "Lao Siang Tian," "Chang Prasan Nga," and other oh songs. He originated the individual playing of seven khims and two ranads. Songs with "oh” sounds in the beginning and songs with lyrics about nature originated from him as well. The examples are "Saen Kam Nueng,” “Tab Poom Ma Rin,” and "Nok Kao Khmer.” He was also the one who brought Thai classical songs into Khmer and studied a number of Khmer songs such as "Nok Kao Khmer,” "Sri Sophon,” “Song Sa Pra Kap,” “Trew,” and “Ang Ko Liak.”

Luang Pradit Phairoh was the first one who brought Angklung from Indonesia into Thailand and then improved it to fit Thai culture. He also brought various songs from Indonesia and adjusted them to fit into the style of Thai orchestra songs. For instance, "Hom Rong Jawa,” “Karad Raya,” "Sama Rung," “Mu Sen Sock,” and "Yawa” are all Indonesian songs improved by him. He also invented sound symbols for teaching Thai classical music by using numbers as written notes; for example number one to seven are used for saw $u$ (coconut fiddle) and saw duang (two-string fiddle) only, and number one to eleven are used for jakay (crocodile-shaped lute). Using numbers makes teaching Thai classical music a lot easier; however this method of teaching was not widely known since it was applied only with his children, grandchildren, and a few other close students. Dr. David Morton, who studied Thai classical music in Thailand for two years and who was a student of Luang Pradit Phairoh (Sorn Silapabanleng), published the notes by University of California, Los Angeles (U.C.L.A.)’s Institute of Musicology's volume entitled “Selected Reports in Ethnomusicology Vol. II, No. 2 (1975).” Moreover, in 1975, Dr. Morton analyzed the song "Nok Kao Khmer" and then got it published by the same Institute entitled “Tradition Music of Thailand” (Morton, 1976: Mode 141).

Apart from having in-depth knowledge of composing songs and improving musical songs, instruments and ensembles, Luang Pradit Phairoh was also a hard-working and generous man who was enthusiastic to improve his knowledge and who dedicated himself to continually passing on his knowledge in Thai classical music (Nimit Osotcharean 2008). Therefore his songs have been beloved through these years. In 1941 after his retirement from the Section of Music Studies, Department of Fine Arts, Ministry of Culture of Thailand, Luang Pradit Phairoh spent his life passing on his knowledge of Thai classical music to his adherents. He was one of the Thai classical music teachers with largest number of students in Thailand. His students also passed on knowledge from him to their followers and also used it as their profession for their lives.

\section{Research Area and Methodology}

This study on Luang Pradit Phairoh's transmission and development of Thai classical music is a qualitative 
research project. The researcher collected information from documents, in-depth interviews, as well as key informants who provided knowledge regarding Luang Pradit Phairoh's transmission of Thai classical music. Key informants are 15 of his direct successors and 13 interviews are of people who are experienced in Thai classical music field such as Thai classical music teachers, players, and scholars who have been trained by Luang Pradit Phairoh's successors.

\section{Research Results}

\subsection{Transmission Methods of Thai Classical Music from Luang Pradit Phairoh}

According to the study, it has been found that Luang Pradit Phairoh passed on his knowledge and culture about Thai classical music in every aspect. He focused on both the cultures and methods of playing and singing Thai classical music. He also hosted Wai Kru ceremonies, which is a ritual arranged in order to pay respect to Thai classical music teachers. In this holy ceremony, students have to bring Kun Gam Non (a small bowl), flowers, joss mallets, candles, and money worth six Thai baht to pay respect to the teachers, specifically on Thursdays. When these students are officially accepted, there will be an annual Wai Kru ceremony which they need to attend because it is believed that paying respect to the teachers before starting learning will grant you a great beginning. This method of transmission is carried by words of mouth and is a casual interaction between the teacher and the student only. The Four Paths of Accomplishment-Aspiration, Effort, Thoughtfulness, and Examination—are used in teaching. Therefore he was lively, satisfied, diligent, and always kept up with his work (Varuesa Lerdsiri, 2004: pp. 7-8). When Luang Pradit Phairoh taught, he always demonstrated and let his student follow from fundamental knowledge to advanced stage. Therefore, they imitated his ways to pass on to their own students. According to Angkana Saeng-anan (2010: p. 98), who wrote her thesis on "Transmission Methods of Thai Classical Music from Uthai Kaewla-iad,” found that Uthai Kaewla-iad gained his knowledge and improves his skills from Luang Pradit Phairoh. Uthai Kaewla-iad is experienced in hosting Wai Kru ceremonies, managing the teaching and learning process such as equipment and locations, and musical instruments, and setting up obligations for Thai orchestra performances at temples, schools, and music performances. He therefore passed on his knowledge and cultures to his own students in the Thai orchestra. This fact corresponds to Wongsuwan's research (2006: p. 116) on transmission methods of Thai classical music from local scholars in Ban Somdej Chaopraya Rajabhat University. It is found that transmission methods of Thai classical music from local scholars are done by oral transmission, demonstration, practice, as well as presentation. Moreover, according to Deananlab's research (2006: pp. 54-55) on transmission methods of Paad bands in Lampang province, transmission methods are done through ancestors and music teachers. For the first vehicle, both grandparents and parents will pass on their techniques to their younger relatives in their own families. For the latter, students have to pay respect to their teachers before learning. In this case, the teachers are, of course, not blood-related to the students, but are experienced in their own fields. If the students respect and trust their teachers, the actual learning process will soon begin. This method of learning corresponds directly to the current "Learning Theory" since it can be applied in any of the teaching processes such as setting a suitable learning environment, persuading, perceiving and so on. There are four aspects in setting the most efficient, effective, appropriate and suitable learning environment to fit with this learning theory.

Firstly, setting an appropriate learning environment helps make students more enthusiastic. It is not only that letting students do practical tasks, finish their given duties, as well as finding more knowledge create more interest in them, but these ways of learning also make them more aware of what they are doing so that they can keep up with their tasks. Students are, therefore, able to gain more knowledge from doing so.

Secondly, to create a suitable environment for these students to learn, students must acknowledge results from what they have done. This way will make them realize whether they have been good or bad when they have played.

Thirdly, giving the students rewards after they have played well in order to show them how success feels like can encourage them to do well again. Lastly, letting students slowly learn new things is also beneficial. Students should learn at a pace that fits their ability whether it is slow or fast. Difference between each student's prowess should be highly considered. Learning this way will provide them more opportunities to become successful as well as make their knowledge and skills become permanent. This corresponds to Shinichi Suzuki's theory (Suzuki, 1898-1998) which concludes that letting children play musical instruments just like their teachers and letting them repeat it over and over will enhance their memory and better their skills. This also corresponds to Carl 
Orff's musical theory. Carl Orff (1895-1982) was the person who invented his famous music teaching methods through the use of xylophones. As it is known that xylophones have different level of notes, therefore children are able to understand rhythm, pitch, and song systems easier. Their hearing ability will soon be improved by listening, singing, as well as playing musical instruments. This corresponds to Chasuwan's research result (2006: p. 178), in which she studied Thai classical music intellectuals on "Ways of Learning and Transmitting Knowledge in Musician's Families."

The research found that the beginning of learning Thai classical music in these families starts from fathers, who will send their children to acclaimed music teachers. For example, Suk, a musician, studied Thai classical music from Sin, Lung Pradit Phairoh (Sorn Silapabanleng)'s father. Siri, Chadin, and Sirikun Worabut, all musicians, studied Thai classical music from Luang Pradit Phairoh. This way of transmission is also a word of mouth and is individual between the teacher and the student. According to Steiner's research (1988: pp. 39-40), it is stated that there are four components in effective learning: teachers, students, contents, and contexts. The essential component is the teacher who not only instructs their ability and passes on their knowledge, but also who guides students to become good people.

Moreover, good teachers are ones who give moral advice so that when their students grow up, they can teach other people and continue their knowledge regarding Thai classical music. This corresponds to Amatayakul's theory (1988: pp. 108-111) regarding "Morals about Thai Classical Music in College" which stated that ways to conserve Thai classical music are to maintain Thai classical music's culture, support the makers of Thai classical music instruments, preserve Thai traditional games that require Thai classical music, protect disappearing old ancient Thai music, and support Thai classical musicians by inviting them to join important events.

\subsection{Development Methods of Thai Classical Music from Luang Pradit Phairoh}

According to this research project, it was found that Luang Pradit Phairoh had a sharp and modern vision. He believed that not doing what people have always been doing was a good way since that would be how Thai classical music can be improved. Moreover he strongly supported learning through the back door in order to improve oneself continually. Luang Pradit Phairoh passed on all of his knowledge without concealing anything. Therefore students would improve themselves if they dedicated themselves to it. Moreover, whoever of his students was ready in terms of age, ability, and morality, he was going to make them teachers in order to pass on their knowledge to others. He was also equally generous to every student. If there was anything he could do to help, he never neglected it. He was always willing to help. For talented students, he would find opportunities for them to show their skills publicly such as letting them have their own shows and compete in major events. Development methods are divided into three main categories: Musicians, Musical Instruments, and Music Development.

\subsection{Musicians' Development}

As stated above, Luang Pradit Phairoh was one of the Thai classical music teachers who had the largest number of students. He passed on his knowledge to his students step by step. For skillful students, he taught them challenging songs without hesitating. His students became successful by creating such wonderful music accomplishments. His students employed his ways of teaching, including his songs, ceremonies about Thai classical music, cultures and traditions, musician's way of life, and teaching by words of mouth as the examples of how they would pass on knowledge to their own students. This corresponds to Taweesuk Sripong's research result (2003: p. 136) in "The Study of Luang Pradit Phairoh as the Main Kong Player" The results in this research showed that Luang Pradit Phairoh's 40 ways of playing Kong (gong) is categorized from fundamental to advanced levels. When students have succeeded and memorized all 40 ways, they will be able to learn other songs far quicker corresponding to the fundamental standard of the Thai classical music profession. This corresponds to Sansani Chasuwan's research result (2006: p. 178) which studied Thai classical music intellects on "Ways of Learning and Transmitting Knowledge in Musician's Families.” The research result shows that there are many types of transmission methods in a musician's family; however all the ways are applied in each different situation. There are two components in music transmission: content and methods. For the first component, in musical families, it depends entirely on the learner. The contents are divided into two parts: songs, morals and social values, and beliefs, depending on the types of students. The professional type of musician student is the experienced one who asks to study a single song. They will receive knowledge according to their skills. However, the 
second type of student is the regular student in school. These students will study songs according to the official government-approved curriculum. However, sometimes other songs are added depending on each student's ability and the preferences of the teacher. The second type of content-morals and social values, and beliefs-will be taught to beginners individually by demonstrating, using word of mouth instruction, written notation, or cassette tapes.

\subsection{Musical Instruments Development}

Luang Pradit Phairoh was the first Thai classical musician who brought Angklung from Indonesia, adapted and improved it so that it can be played in Thailand. He began by teaching royal pages in Burapa Pirom Palace. When his students were good enough to perform publicly, they did so in front of His Majesty the King at that time at Rajadivas Temple during Royal Kathin ceremonies. He also improved the classical Mon orchestra which consisted chiefly of the gamelan. Before his innovations, there used to be only kong morn and perng drums being played on the floor; however he improved it by adding perng drums and krajung mong, making the orchestra far more beautiful. This brought more income to the orchestra since there were more people paying them to play this music during their important events. Therefore musicians could have a profitable career (Narkong, 1995: pp. 55-56). The adjustment of ways of playing, the use of foreign musical instruments to merge with the classical Thai orchestra, as well as the improvement of transmitting and musicians' ways of living all have influenced the enriched cultural exchange. This corresponds to Ralph Linton's theory on "Cultural Expansion” which states that cultural expansion is the result of the relationship between societies, causing cultural acculturation. When time goes by, the combination of cultures then takes place. The social adjustment like this corresponds to August Comte's social evolution theory which states that social adjustment happens from two components: the alteration and the survival (the remaining traditions) because some people still believe in the same old cultural ways.

\subsection{Music Development}

Luang Pradit Phairoh developed new and improved techniques from great teachers to play ranat-ek. The examples are constantly hitting the same notes quickly but softly, changing three notes at the same time, adding more notes in one section, continually hitting notes, using an adjustable amount of force when hitting notes with the mallets, and changing the way to hold the mallets to produce different tones and notes. This is counted as one of the major evolutions in playing ranat-ek. Moreover, Luang Pradit Phairoh made ranat-ek more prominent in the Thai orchestra. There are many ranat-ek songs which he created that show the effectiveness of ranat in the history of Thai classical music, including Ah Nu (using two bars of ranat), Toy Roob, Lao Pan, Paya Sok, Krao Nai, Cherd Nork, Kaek Morn, Hok Bot, Ma Yong, and many other beloved songs.

Luang Pradit Phairoh changed the old "Khmer Kao Kiaw" from two bars to three bars by using softer and smoother tones. Since it produced such differences for this song, he then renamed it to "Khmer Liab Nakorn." In 1915, he invented Rub and Oh songs. He also started composing songs with three and four bars such as "Pama Ha Torn 4 Bars," "Prahm Deed Nam Tao 4 Bars," "Dao Jorake 4 Bars,” and "Khmer Sai Yoke 4 Bars.” Furthermore, he improved more than ten other Thai classical songs to Tao suites. And he also put lyrics in his newlycomposed songs.

Luang Pradit Phairoh originated the individual playing of seven khim (dulcimers) and two ranat. He also originated songs with oh sounds in the beginning and songs with lyrics about nature, such as "San Kamnueng," "Tub Poomrin," "Nok Kao Khmer." He was also the one who brought Thai songs into Khmer and studied a number of Khmer songs, such as "Nok Kao Khmer," "Sri Sophon,” "Song Sa Prakaep," "Trew," and "Ango Liak." He was the first one who brought Angklung from Indonesia, adjusted and improved it to match Thai music. He memorized various Indonesian songs and recomposed them to fit to Thai orchestra; for instance "Hom Rong Jawa," "Karad Raya," "Sama Rung," "Mu Sen Sok," and "Yawa."

Luang Pradit Phairoh invented symbols to substitute notes in Thai classical music teaching by using numbers as notes. For example, number 1 to 7 are for saw $u$ and saw duang only, and numbers 1 to 11 are for jakay. Using numbers to substitute notes like this makes studying Thai classical music a lot easier; however it was not widely used since Luang Pradit Phairoh used this method only for his children, grandchildren and close students. Lady Shin Silapabanleng once said, "I studied Thai classical music by using nine notes which my father invented for teaching the Rajini School's students. He taught how to hold saw and how to use its mallets correctly by not spreading your fingers too wide. Therefore I am able to play various songs which other people need to 
use notation to play. Playing with notation makes it easier to memorize each song since there are high and low notes. My father had never been trained to become a teacher; however his methods of teaching depend on each student's prowess, intellect, as well as behavior. Therefore his students play the same song differently. This method coincidentally matches the new way of teaching. Even the nine notes match perfectly with the international Survey notes.” (Narkong \& Sakrik, 2004: p. 27)

Luang Pradit Phairoh respected Soom as the master in the Thai orchestra field. Therefore he passed on Mon songs which he studied from Soom to his fellow students. Moreover, he invented a large number of Thai songs with the characteristic Mon accent. This incident caused the sudden popularity of the Mon ensemble. Eventually, Mon songs became the major component in Thai classical musicians' repertoire. This corresponds to Somsak Srisuntisuk's study (2001: 23-24) on "Society and Culture: Ideas, Practicality, and Theory." It was found that cultural integration is the process which slowly accepts foreign cultures into its own practical application. This reduces cultural conflicts when two groups of people with different cultures become related. Generally, those who have less financial and political power tend to adjust themselves to those who have more. However, some changes occur because of the society's needs. This corresponds to Amatayakul's theory (1988: pp. 108-111) in an article titled "Morals in Thai Classical Music in College," which states that ways to promote Thai classical music are to support playing Thai classical music instruments, provide knowledge to the public to make them understand Thai classical music more, use Thai classical music in Thai performances and games, and provide knowledge to listeners so that they know more about what they are listening.

\section{Conclusion}

Since this research is about Luang Pradit Phairoh (Sorn Silapabanleng), knowledge from different kinds of fields -that is music culture, traditions, beliefs, ways of living, preservation, supporting and improving musiciansis re-iterated. Therefore, this research is helpful to both state and private organizations such as community leaders, temples, schools, universities, as well as cultural centers in each province. The major aims of this research are to maintain and promote Thai classical music education and benefits, support human resources like Thai classical music teachers, improve musical instruments, and improve transmission methods to become more accessible by using modern technology. There is much more about the work of Luang Pradit Phairoh which can be studied. However from my personal experience, preserving and improving cannot be done by oneself. There needs to be collaboration between state and private organizations, as well as communities, temples and cultural centers. Furthermore, preserving and supporting Thai classical music would hopefully strengthen relationships and cultures worldwide. By doing so, we can improve and change social relations in the future.

\section{References}

Amatayakul, P. (1988). Morals about Thai Classical Music in College. 20th Dontrithai in University, 108-111.

Chasuwan, S. (2006). The Intellectual Knowledge in Thai Classical Music: Patterns of Learning and Knowledge Transferring of Nuk Dontri Family (p. 178). Bangkok: Rajabhat Suansunantha University.

Deananlab, P. (2006). The Transmission of Pad in Muang District, Lampang Province. Thesis, Bangkok: Sirnakharinwirot University.

Lerdsiri, V. (2004). Luang Pradit Phairoh (Sorn Silapabanleng) (pp. 7-8). Master Thesis, Maha Sarakham Province: Mahasarakham University.

Morton, D. (1976). The Traditional Music of Thailand. Chapter 14, Pitch Outline, “Nok Khao Khamae” (thao) Mode 141. Berkeley: University of California Press.

Narkong, A. (1995). Pipaht Mon and Phleng Mon: Historical Study and the Present Situation among Common Thai Musicians. In Music Journal (June), Bangkok: Mahidol University.

Narkong, A., \& Sakrik, A. (2004). Luang Pradit Phairoh (Sorn Silapabanleng). Bangkok: Matichon Printing Co.

Saeng-anan, A. (2010). Transmission Methods of Thai Classical Music from Uthai Kaewla-iad. Doctoral Dissertation, Maha Sarakham Province: Mahasarakham University.

Samganan, A. (2010). A Transfer of Kru Uthai Kaewla-iad's Thai Music Style: A Case Study of Thai Banleng Ensemble, Amphoe Amphawa, Changwat Samut Songkhram. Master Thesis, M.F.A. (Ethnomusicology). Bangkok: Srinakarinwirot University.

Sripong, T. (2003). Luang Pradit Phairoh (Sorn Silapabanleng) (p. 136). Master Thesis, M.F.A. (Ethnomusicology), Bangkok: Srinakarinwirot University. 
P. Pootong et al.

Steiner, E. (1988). Methodology of Theory Building (pp. 39-40). Sydney: Educology Research Associates.

Suzuki, S. (1998). Shinichi Suzuki: His Speeches and Essays. Los Angeles, CA: Alfred Music.

Wongsuwan, K. (2006). A Study of the Transmission Methods of Thai Musical Instruments by Local Scholars in Rajaphat Ban Somdej Chaopraya University. Thesis Major: Development Education. 